Jurnal ABDINUS : Jurnal Pengabdian Nusantara, 3 (1), 2019, 11-19

Available online at:http://ojs.unpkediri.ac.id/index.php/PPM

DOI: https://doi.org/10.29407/ja.v3i1.12768

\title{
Peningkatan Kemampuan Menggambar Teknik Siswa SMK Menggunakan Software Berbasis Computer Aided Design (CAD)Sebagai Upaya Pengembangan Kualitas Nilai Sumber Daya Manusia (SDM) Untuk Menghadapi Dunia Kerja
}

\author{
Rahayu Mekar Bisono ${ }^{1^{*}}$, Devina Rosa Hendarti ${ }^{2}$ \\ ${ }^{1 *}$ rahayuyudhaputra@gmail.com \\ ${ }^{1,2}$ Teknik Mesin \\ ${ }^{1,2}$ POLINEMA PSDKU Kediri
}

Received: 0507 2019. Revised: 1908 2019. Accepted: 28082019

\begin{abstract}
This program was held aimed at improving the competency of technical drawing of vocational students in the Municipality of Kediri. Competence in this service consists of three aspects, namely affective, cognitive, and psychomotor. This program is carried out with a model of meeting in the classroom, giving theory, practicum, performance of making parts with image models and real object models. The improvement of students' abilities was measured using observation sheets of student activities to determine the improvement of the affective aspects of students, the pretest and posttest instruments to determine the increase in cognitive aspects of students, the worksheets of students to determine the improvement of psychomotor aspects. The first output of this program is to increase the ability of vocational students in the field of mechanical engineering with the help of computers using CAD-based software. The next output is a competency certificate that will be given to students in accordance with their competencies.
\end{abstract}

Keywords: Service, Competence, Technical drawing, CAD

\begin{abstract}
Abstrak: Pengabdian ini diadakan bertujuan untuk meningkatkan kompetensi menggambar teknik siswa SMK se Kotamadya Kediri. Kompetensi dalam pengabdian ini terdiri dari tiga aspek yaitu afektif, kognitif, psikomotorik. Pengabdian kepada masyarakat ini dilaksanakan dengan model pertemuan di dalam kelas, pemberian teori, pelaksanaan praktikum, unjuk kerja pembuatan part dengan model gambar dan model objek nyata. Peningkatan kemampuan siswa diukur menggunakan lembar observasi aktivitas siswa untuk mengetahui peningkatan aspek afektif siswa, instrumen pretest dan posttest untuk mengetahui peningkatan aspek kognitif siswa, lembar kerja siswa untuk mengetahui peningkatanaspek psikomotorik. Luaran pertama dari program ini adalah peningkatan kemampuan siswa SMK dalam bidang gambar teknik mesin dengan bantuan komputer menggunakan software berbasis CAD. Luaran selanjutnya adalah berupa sertifikat kompetensi yang akan diberikan kepada siswa sesuai dengan kompetensi yang dimiliki
\end{abstract}

Kata kunci: Pengabdian, Kompetensi, Gambar teknik, CAD 


\section{ANALISIS SITUASI}

Persaingan dalam dunia kerja semakin ketat beriringan dengan globalisasi yang terus berkembang. Penambahan jumlah lapangan pekerjaan yang terbatas tidak dapat menutupi penambahan jumlah pencari kerja yang lebih banyak sehingga menuntut sumber daya manusia (SDM) yang berkualitas tinggi agar dapat terus bersaing. Keunggulan suatu negara saat ini juga tidak lagi ditandai dengan melimpahnya sumber daya alam (SDA) yang dimilikinya, melainkan pada keunggulan SDM nya.

Sumber daya manusia merupakan dasar untuk membangun suatu negara menjadi lebih baik lagi. Sumber daya manusia yang unggul dan berkualitas tinggi, dapat membuat suatu negara mampu bersaing dalam dunia kerja dengan negara-negara lain. Peningkatan kualitas sumber daya manusia dapat dilakukan dalam berbagai hal, salah satu cara peningkatannya adalah di dunia pendidikan. Dalam dunia pendidikan inilah seseorang dapat memantaskan diri diri, mengembangkan seluruh potensi yang dimiliki, yang nantinya akan sangat berguna bagi masa depannya terutama dalam dunia kerja.

Pendidikan dapat meningkatkan nilai SDM pelakunya. Dewasa ini, di Indonesia marak dikembangkan pendidikan vokasi di perguruan tinggi dan kejuruan di tingkat SLTA. Ini merupakan salah satu cara peningkatan sistem pendidikan seperti halnya semakin baiknya pendidikan di sekolah menengah kejuruan (SMK). Pendidikan di SMK bukan hanya materi pembelajaran saja yang diberikan, namun juga keterampilan pada suatu bidang tertentu. Dalam pendidikan SMK, siswa dapat menyalurkan potensi, minat, dan bakat yang dimiliki agar dapat berkembang dan menjadikan sebuah skill yang berkualitas dan berguna untuk di dunia kerja nanti.

Salah satu keterampilan yang harus dimiliki oleh siswa SMK khususnya SMK paket keahlian Teknik Pemesinan dan Teknik Kendaraan Ringan adalah menggambar teknik. Dalam pembuatan sebuah komponen mesin diperlukan adanya perencanaan yang matang. Menggambar bentuk komponen merupakan perencanaan yang vital agar dapat memperhitungkan nilai estetika dari desain yang dibuat, perkiraan kebutuhan material, kebutuhan pengeluaran untuk produksi, dan juga beberapa aspek penting lainnya. Gambar dalam teknik pemesinan juga bias disebut bahasa teknik, di mana berfungsi untuk meneruskan keterangan-keterangan secara tepat dan objektif. Keterangan-keterangan tersebut dinyatakan dalam bentuk lambang-lambang (Lestari, 2013:29).

Sebagai bahasa teknik, gambar perlu disajikan dalam bentuk tiga dimensi agar dapat lebih dipahami oleh pengguna. Hartanto (1999:54) mengatakan bahwa kadang-kadang 


\section{Jurnal ABDINUS : Jurnal Pengabdian Nusantara, 3 (1), 2019, 11-19}

Rahayu Mekar Bisono, Devina Rosa Hendarti

diperlukan gambar-gambar dalam tiga dimensi dari sebuah benda, untuk mendapatkan gambaran dari bentuk bendanya. Sebelum berkembangnya menggambar teknik menggunakan komputer, masih marak dilakukan menggambar teknik dengan cara manual, yaitu hanya berbekal alat gambar dan kemampuan untuk menggambar. Hal ini tentu saja mempunyai banyak kekurangan daripada kelebihannya jika dikomparasi dengan menggambar teknik menggunakan komputer. Pengeluaran biaya operasional dan banyaknya waktu yang dibutuhkan menjadi kendala utama menggambar teknik dengan manual. Meskipun jika menggunakan komputer juga dibutuhkan perlengkapan yang mengeluarkan biaya yang tidak sedikit, tapi efektifitas waktu dan banyaknya projek yang dihasilkan dapat menutupi kendala biaya yang sebelumnya. Terdapat beberapa permasalahan yang terdapat dalam hal ini, diantaranya adalah sebagai berikut.

a. Kurangnya fasilitas penunjang pembelajaran di tingkat SMK yang berkaitan dengan menggambar teknik dengan bantuan komputer menjadikan nilai SDM siswa dalam bidang ini menjadi tidak maksimal

b. Terbatasnya informasi mengenai pentingnya pengetahuan terkait gambar teknik menggunakan komputer dalam dunia industri

c. Pemerataan kualitas SDM pendidik di setiap SMK yang terlalu jauh dalam bidang ini, sehingga mengakibatkan kesenjangan pengetahuan antar siswa SMK

d. Tingkat urgensitas kebutuhan tenaga drafter dari tingkat SMK di dunia Industri

e. Banyaknya peluang usaha mandiri di bidang ini yang kurang bisa dioptimalkan karena daya SDM yang rendah

Akhirnya, menggambar teknik menggunakan komputer dewasa ini menjadi pilihan penting dalam dunia industri. Karena banyak aspek yang lebih dapat diperhitungkan daripada menggambar manual, seperti berat benda, jenis material dapat diubah suai kebutuhan dengan cepat, melakukan modifikasi dengan lebih efektif dan banyak keuntungan lainnya. Salah satu upaya yang dilakukan adalah dengan adanya CAD (Computer Aided Design). Computer Aided Design (CAD) adalah penggunaan sistem komputer untuk membantu dalam pembuatan, modifikasi, analisis, atau optimalisasi dari sebuahdesain (Narayan, 2008:3). Perangkat lunak CAD digunakan untuk meningkatkan produktifitas dari desainer, meningkatkan kualitas dari desain, meningkatkan komunikasi melalui dokumentasi,dan untuk menciptakan suatubasis data untuk kegiatan manufaktur (Narayan, 2008:4).CAD dapat digunakan untuk mendesain kurva dan gambar dalam bentuk gambar dua dimensi (2D) maupun pejal atau gambar tiga dimensi (3D) (Duggal, Vijay (2000). 


\section{Jurnal ABDINUS : Jurnal Pengabdian Nusantara, 3 (1), 2019, 11-19}

Rahayu Mekar Bisono, Devina Rosa Hendarti

Hal inilah yang mendasari kenapa program ini harus diadakan. Agar kemampuan siswa dalam hal menggambar teknik lebih meningkat, perlu kiranya diadakan program Peningkatan Kemampuan Menggambar Teknik Siswa SMK menggunakan Software Berbasis Computer Aided Design (CAD) sebagai Upaya Pengembangan Kualitas Nilai Sumber Daya Manusia (SDM) untuk Menghadapi Dunia Kerja.

\section{SOLUSI DAN TARGET}

Permasalahan pada pengabdian ini antara lain tingkat SDM yang tidak maksimal akibat fasilitas yang kurang dapat diminimalisasi dengan mengikutkan siswa pada program ini, karena dalam program ini disediakan fasilitas penunjang sesuai kebutuhan.Terbatasnya informasi mengenai pentingnya pengetahuan terkait gambar teknik menggunakan komputer dalam dunia industri, hal ini akan dapat diatasi dengan memberikan informasi seluas-luasnya dalam program ini, dan membuka wawasan siswa agar dapat pro aktif dalam mencari informasi.Kesenjangan pengetahuan antar siswa SMK juga dapat diminimalisasi dengan mengikuti program ini.Siswa yang mempunyai kemampuan dalam bidang ini dapat ikut berkompetisi untuk menjadi drafter dari tingkat SMK di dunia Industri.Banyaknya peluang usaha mandiri di bidang ini yang kurang bisa dioptimalkan karena daya SDM yang rendah, hal ini juga dapat ditingkatkan dengan adanya program ini, sehingga siswa yang benar-benar tertarik dan mempunyai kemampuan dalam bisang ini dapat membuka sendiri usaha mereka.

Berdasarkan paparan di atas, rencana kegiatan program peningkatan kemampuan menggambar teknik siswa SMK menggunakan software berbasis computer aided design (CAD) sebagai upaya pengembangan kualitas nilai sumber daya manusia (SDM) untuk menghadapi dunia kerja dapat dijabarkan sebagai berikut.

1. Sosialisasi rencana kegiatan

2. Pembuatan materi dan modul

3. Pemberian materi tentang penggunaan software berbasis computer aided design (CAD)

4. Evaluasi peningkatan kemampuan siswa

5. Evaluasi program

6. Pembuatan laporan

Pengabdian masyarakat ini diadakan di Laboratorium Desain Jurusan Perawatan dan Perbaikan Mesin Politeknik Kediri pada bulan Agustus sampai dengan 


\section{Jurnal ABDINUS : Jurnal Pengabdian Nusantara, 3 (1), 2019, 11-19}

Rahayu Mekar Bisono, Devina Rosa Hendarti

September 2018, dengan objek pengabdian adalah siswa SMK paket keahlian Teknik Pemesinan dan Teknik Kendaraan Ringan.

\section{METODE PELAKSANAAN}

Kegiatan peningkatan kemampuan menggambar teknik siswa SMK menggunakan Software Berbasis Computer Aided Design (CAD) sebagai upaya pengembangan kualitas nilai sumber daya manusia (SDM) untuk menghadapi dunia kerja. Untuk lebih jelasnya akan diuraikan dalam rincian berikut.

\section{Sosialisasi rencana kegiatan}

Sasaran dari kegiatan ini adalah siswa SMK paket keahlian Teknik Pemesinan dan Teknik Kendaraan Ringan di Kotamadya Kediri. Sosialisasi dilakukan melalui pengiriman surat undangan dan pemberian penjelasan kepada pihak sekolah dan atau guru terkait yang dapat dihubungi. Dengan adanya sosialisasi ini penjabaran jenis, model, dan tujuan kegiatan dapat tersampaikan dengan baik. Sosialisai kegiatan dilaksanakan pada bulan Nopember 2018.

\section{Pembuatan materi dan modul}

Pembuatan materi dan modul dilakukan oleh tim pelaksana pengabdian kepada masyarakat bersama pembantu lapangan yang selanjutnya juga berperan sebagai pemateri pelatihan peningkatan kemampuan menggambar teknik siswa SMK menggunakan Software Berbasis Computer Aided Design (CAD) sebagai upaya pengembangan kualitas nilai sumber daya manusia (SDM) untuk menghadapi dunia kerja.

Pembuatan modul dilakukan selama dua bulan pada bulan Oktober-Desember 2018 melalui beberapa kajian literatur, kajian kebutuhan skill siswa SMK untuk memasuki dunia kerja, dan juga kajian beberapa materi yang sudah disampaikan melalui bangku sekolah. Dengana adanya kajian ini, maka keberhasilan pelaksanaan kegiatan diharapkan mampu mencapai tujuan yang diharapkan sehingga mendatangkan manfaat bagi peserta dan juga tim pelaksana.

3. Pemberian materi tentang penggunaan software berbasis computer aided design (CAD)

Materi diberikan melalui skema tutor teaching, di mana terdapat tutor yang memberikan penjelasan materi kepada peserta. Skema tutor teaching ini berbasis pada teacher learning center, di mana pusat pembelajaran berada pada tutor. Akan tetapi juga berjalan dua arah di mana peserta diberikan keleluasaannya untuk menyampaikan pendapat atau bertanya. 


\section{Jurnal ABDINUS : Jurnal Pengabdian Nusantara, 3 (1), 2019, 11-19}

Rahayu Mekar Bisono, Devina Rosa Hendarti

Materi diberikan selama beberapa sesi sesuai dengan penjabaran materi yang ada di modul, di mana setiap akhir sesi diakhiri dengan pemberian tugas dan evaluasi untuk mengukur pemahaman materi yang diserap oleh peserta.

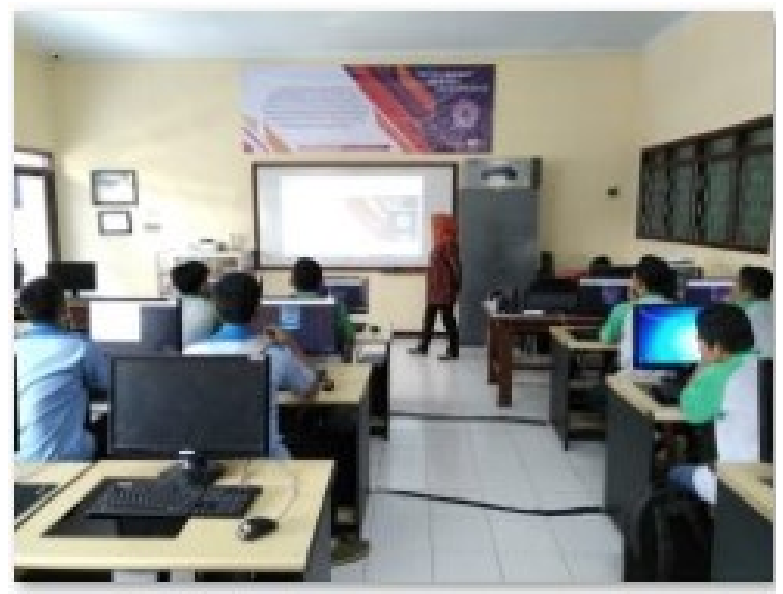

Gambar 1. Pembukaan

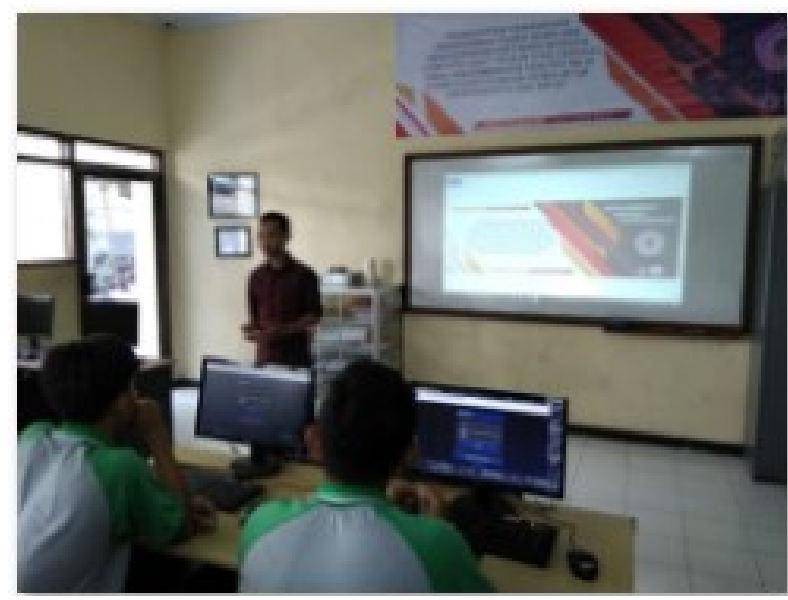

Gambar 3. Penjelasan Awal

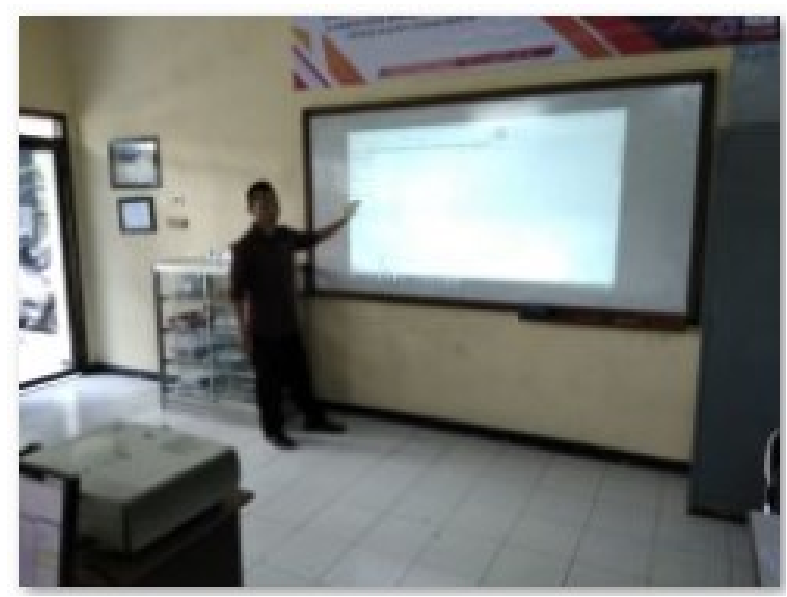

Gambar 5. Pemberian Materi

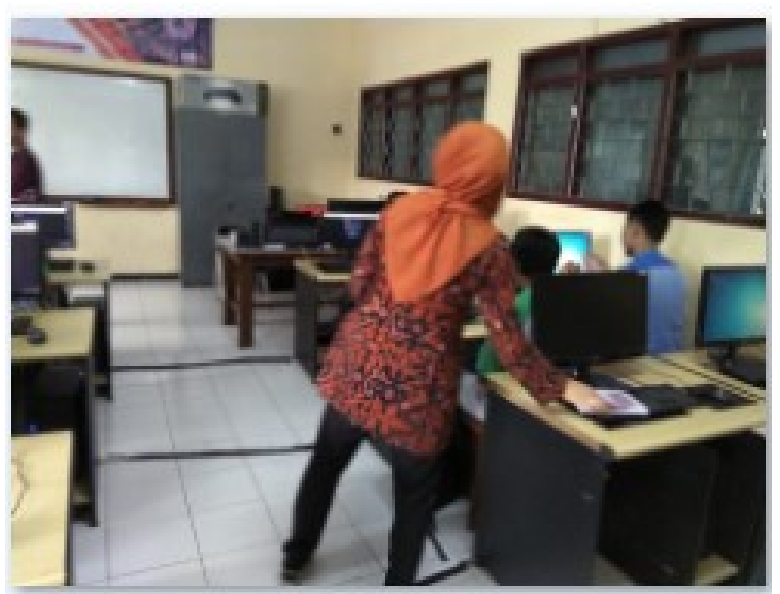

Gambar 2. Pembagian Modul

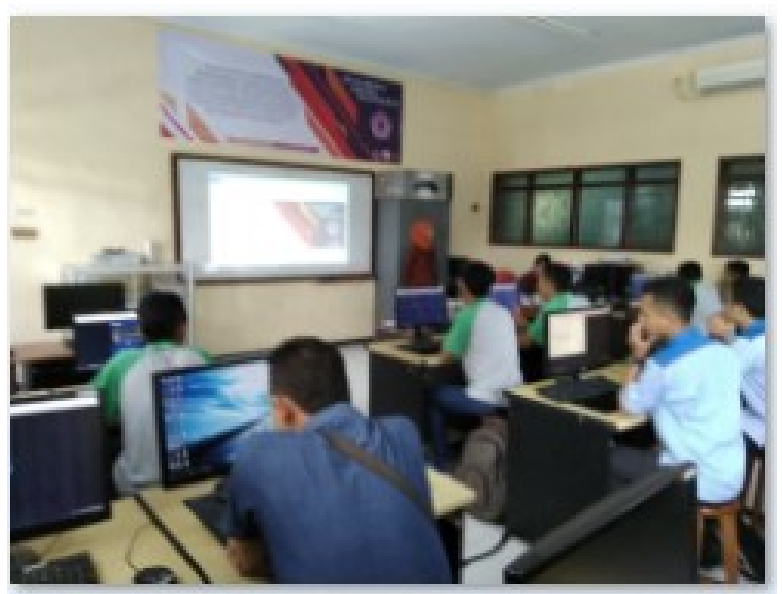

Gambar 4. Peserta Memperhatikan

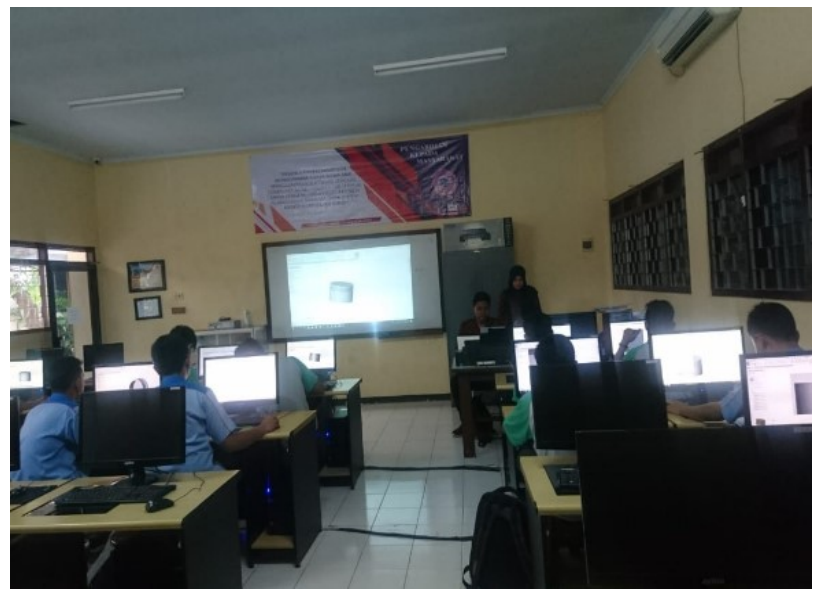

Gambar 6. Memperhatikan Materi 


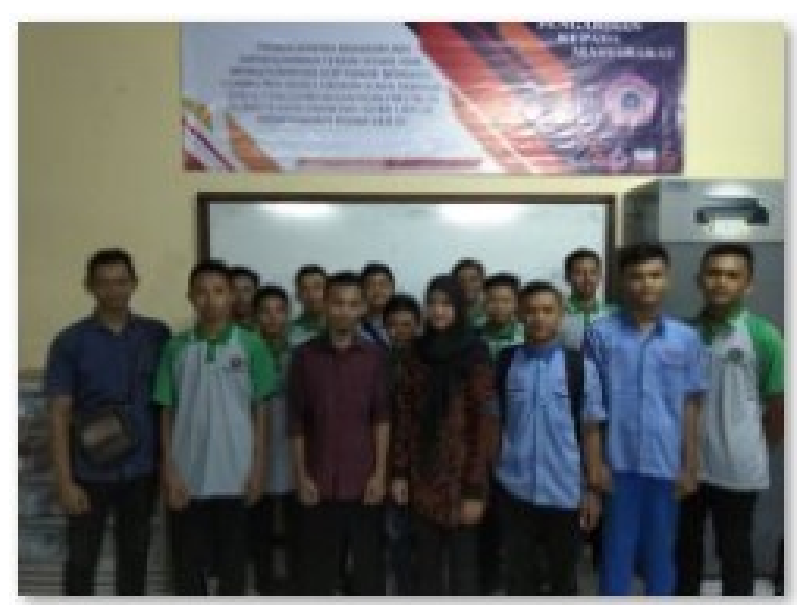

Gambar 7. Foto Penutupan

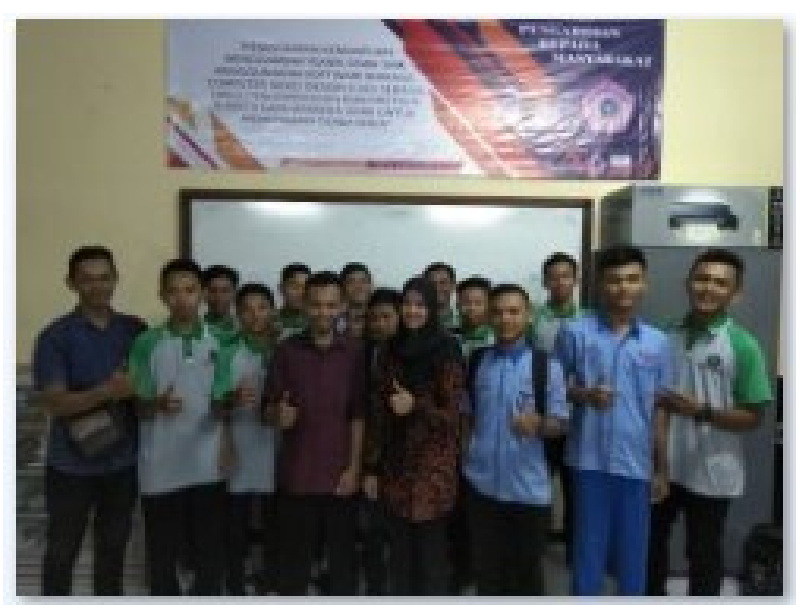

Gambar 8. Foto Bersama

\section{HASIL DAN LUARAN}

Hasil kegiatan pengabdian kepada masyarakat ini dihadiri oleh 13 peserta dari 20 peserta yang terdaftar. Kegiatan diawali dengan sosialisasi yang dilaksanakan pada tanggal 30 Agustus 2018 bertempat di SMK Al-Huda Kediri. Kegiatan berlangsung dengan lancar dan sekolah sangat antusias dengan sosialisasi yang diberikan. Selain pemberian materi terkait olahan pepaya, diberikan pula beberapa pengetahuan tentang desain mesin menggunakan bantuan komputer, terutama program yang akan digunakan saat pelatihan.

Pembuatan modul berlangsung pada bulan Oktober-November 2018. Modul ini selanjutnya akan digunakan sebagai sarana penyampaian informasi kepada peserta agar pelatihan dapat berjalan dengan lancar. Modul berisi dasar-dasar menggambar mesin menggunakan komputer sampai dengan tingkat intermediate. Selanjutnya setiap peserta akan diberikan modul tersebut sebagai pegangan baik saat pelatihan atau pasca pelatihan.

Pelatihan dilaksanakan pada bulan Desember 2018 di ruang laboratorium gambar komputer Politeknik Kediri. Pelatihan berjalan dengan lancar dibuktikan dengan antusiasme peserta dan kompetensi peserta yang meningkat, sebelum dan sesudah pelatihan. Berikut adalah beberapa karya peserta yang dibuat ketika pelatihan. 


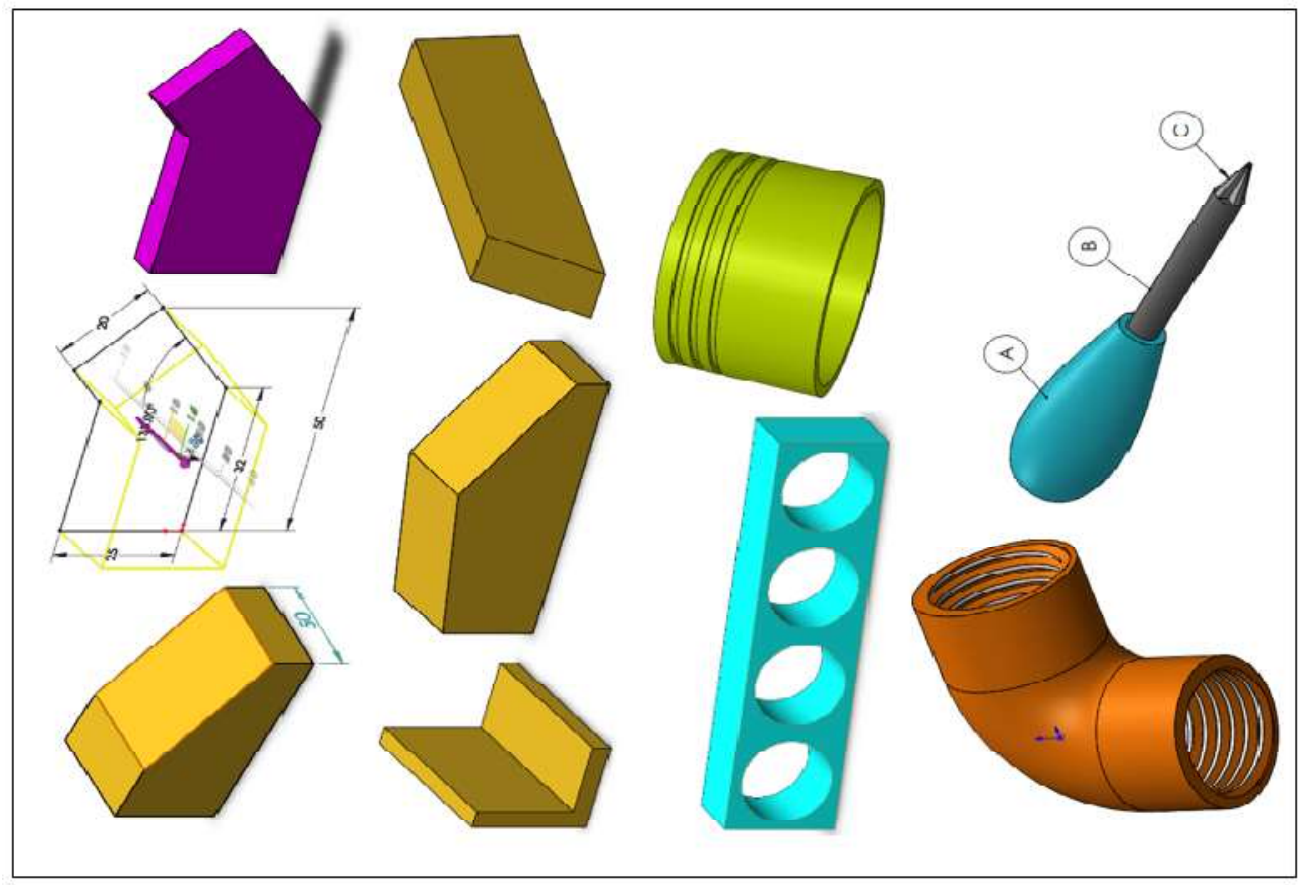

Gambar 10. Karya Peserta

\section{SIMPULAN}

Simpulan yang diperoleh dari kegiatan Pengabdian Kepada Masyarakat ini adalah:

1. Khalayak sasaran mengenal software berbasis CAD baru setelah adanya kegiatanini.

2. Pelatihan dapat meningkatkan pengetahuan khalayak sasaran mengenai software CAD baru dan menggambar teknik yang lebih efektif dan efisien menggunakan komputer sebesar $90 \%$

3. Keterampilan khalayak sasaran dalam menggambar teknik meningkat.

Meningkatkan kemampuan khalayak sasaran dalam membuat sketsa gambar

\section{DAFTAR RUJUKAN}

Duggal, Vijay. 2000.Cadd Primer: A General Guide to Computer Aided Design and DraftingCadd, $C A D$

Hartanto, N. Sugiarto, dan Takeshi Sato. 1999. Menggambar Mesin Menurut Standar ISO. Jakarta: Balai Pustaka

Lestari, WD. 2013. Kontribusi Teknik Pengukuran dan Membaca Gambar Kerjaterhadap Hasil Belajar Praktikum Pemesinan di SMKN 1 Trenggalek. Tidak diterbitkan. Fakultas Teknik. Universitas Negeri Malang 
Jurnal ABDINUS : Jurnal Pengabdian Nusantara, 3 (1), 2019, 11-19

Rahayu Mekar Bisono, Devina Rosa Hendarti

Narayan, K. Lalit. 2008.Computer Aided Design and Manufacturing. New Delhi: Prentice Hall of India. 